\title{
Strong indications for nonlinear dynamics during Dansgaard-Oeschger events
}

\section{H. Braun}

Heidelberg Academy of Sciences and Humanities, Heidelberg, Germany

Centre for Ice and Climate, Niels Bohr Institute, University of Copenhagen, Denmark

Received: 31 May 2009 - Accepted: 11 June 2009 - Published: 1 July 2009

Correspondence to: H. Braun (holger.braun@iup.uni-heidelberg.de)

Published by Copernicus Publications on behalf of the European Geosciences Union.
$5,1751-1762,2009$

Nonlinear dynamics during DO events

H. Braun

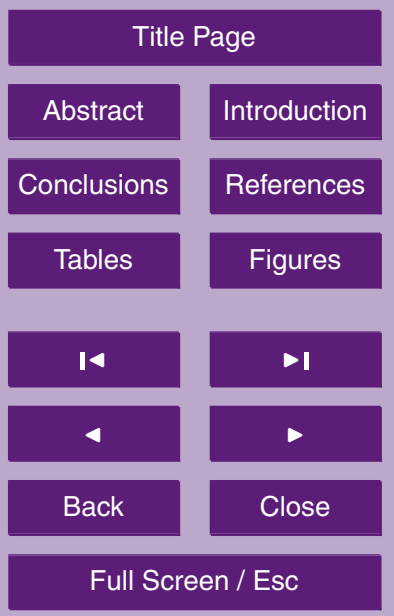

Printer-friendly Version

Interactive Discussion 


\section{Abstract}

Many climate records show the occurrence of large amplitude (10-15K), millennialscale warming events during glacial times, the Dansgaard-Oeschger (DO) events. So far these events have almost exclusively been investigated by means of linear time se5 ries analysis. The scope of this paper is to test if the assumption of linearity is fulfilled during DO events. By means of a surrogate-based Monte Carlo method, I here demonstrate that the 60000 -year long $\delta^{18}$ O-record from the NGRIP ice core from Greenland allows to reject the null hypothesis of linearity beyond any reasonable level of doubt. Instead, the ice core record supports the interpretation that the events represent regime switches between different states of operation of glacial climate. As a conclusion, future studies on DO events should focus on the development and the application of more adequate (i.e., nonlinear) methods of time series analysis.

\section{Introduction}

Many climate records, e.g. ice cores, deep sea sediments and speleothems, show the

existence of large amplitude (10-15 K), millennial-scale oscillations in glacial climate, the Dansgaard-Oeschger (DO) events, cf. Fig. 1a (Dansgaard et al., 1982; Grootes et al., 1993; Bond et al., 1993; Spötl and Mangini, 2002). The common interpretation is that these events represent regime switches (Oeschger et al., 1984; Broecker et al., 1985; Alley et al., 2003), which implies a highly nonlinear dynamical scenario, i.e. a scenario in which the response of the climate system is not proportional to the forcing. Despite to apparent nonlinearity of the events, methods of linear time series analysis have so far almost exclusively been applied by the paleoclimate community to investigate DO events. For example, the 1470-year spectral peak in the GISP2 ice core was estimated as being statistically significant beyond the $99 \%$ level, based on the assumption of red noise (Grootes and Stuiver, 1997; Schulz, 2002). However, it is well known in the nonlinear community that the use of simple linear methods to analyse
$5,1751-1762,2009$

\section{Nonlinear dynamics during DO events}

H. Braun
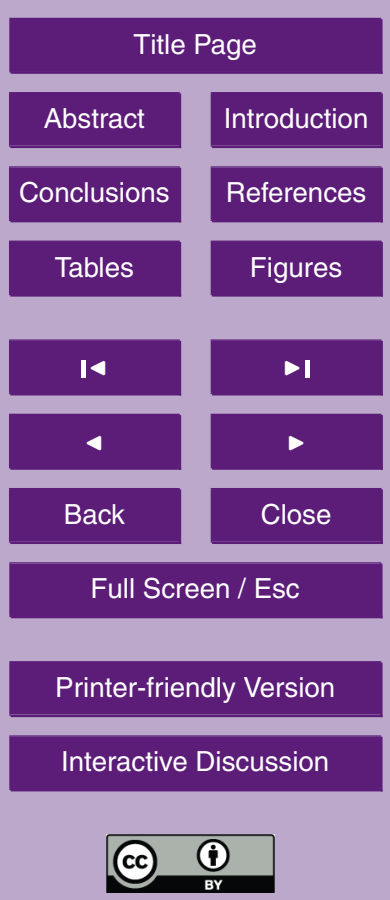
highly nonlinear processes can lead to fundamentally wrong conclusions. In this light it is of importance to investigate on pure statistic grounds if DO events are nonlinear or are better explained by a simple linear dynamical scenario, which can be confused with true regime shifts.

\section{Methods and results}

Here I use a 60000 -year long bi-decadal $\delta^{18}$ O-record from the NGRIP ice core from Greenland, a standard paleo-temperature proxy, to perform a test of nonlinearity. The study focusses on the time interval between 11000 and 60000 years before present (BP). During this interval, DO events are a persistent feature of the time series, cf. Fig. 1a (Svensson et al., 2008). In contrast, no events occur in the younger part of the ice core record, during which Greenland climate is much warmer and shows considerably smaller anomalies than in the glaical part between 11000 and 60000 years BP. The younger part between 0 and 11000 years BP is therefore neglected in this study. For the analysis, the $\delta^{18} \mathrm{O}$-record is smoothed by applying a 5 -point running average, 15 in order to remove the highest frequency variations. The smoothed record is then investigated by means of null-hypothesis testing.

The basic concept of null-hypothesis testing is as follows (Kantz and Schreiber, 1997; Ditlevsen, 2007): (i) A plausible null-hypothesis is stated which might explain a given data set. The standard null-hypothesis is that the data result from a random linear process, e.g. from an autoregressive process. (ii) A test statistic is defined, based on which the null-hypothesis is tested. In principle, the test statistic can be any function which assigns a real number to a time series. (iii) The distribution of the test statistic is calculated or numerically estimated under the assumption that the null-hypothesis is correct. (iv) If the value of the test statistic as calculated from the data set falls into
$5,1751-1762,2009$

\section{Nonlinear dynamics during DO events}

H. Braun

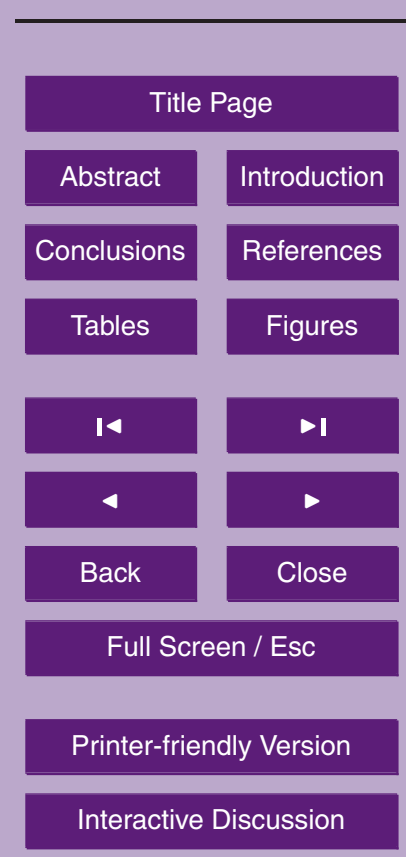
ample), the null-hypothesis is rejected with probability 1-p, in favour of an alternative hypothesis. Otherwise it is not possible to reject the null-hypothesis. Of course, be- 
ing able to reject the null-hypothesis does not necesssarily imply that the alternative hypothesis is correct, since more than one alternative hypothesis might exist.

Here the null-hypothesis is that DO events result from a random, linear, time-invariant process. The test statistic is the mean value $M$ of the absolute difference (in $\delta^{18} \mathrm{O}$ units) 5 between two consecutive data points in the NGRIP $\delta^{18}$ O-record: $M=1 / N \cdot \sum_{n}\left|x_{n+1}-x_{n}\right|$, where the sum is over all data points and $N=2447$ is the total number of data points in the time interval under investigation. For the NGRIP $\delta^{18} \mathrm{O}$ record (Fig. 1a), the value $M_{\text {NGRIP }}=0.226$ of the test statistic is found. To obtain the distribution of the test statistic, a surrogate-based Monte Carlo simulation with a phase-randomization approach is 10 performed (Kantz and Schreiber, 1997): The observed time series of DO events in the ice core data is transformed into the frequency domain by means of a standard Fourier transformation (Fig. 1b). To obtain a surrogate time series, each spectral component of the NGRIP $\delta^{18} \mathrm{O}$ time series is then assigned a random phase between 0 and $2 \pi$. The randomized surrogate is transformed back into the time domain (Fig. 2a), in which 15 the value of the test statistic is calculated. For each single surrogate time series, this randomization procedure is repeated, which finally yields the distribution of the test statistic (Fig. 3). The chosen procedure ensures that each surrogate time series has the same amplitude spectrum as the observed time series (compare Fig. $1 \mathrm{~b}$ and $2 \mathrm{~b}$ ) and that the phase of each spectral component in the surrogate time series is random.

20 This approach is consistent with the considered null-hypothesis, because in a linear time-invariant system each sinusoidal component in the forcing results in an output component of the same frequency, so that a random input (which has a random phase for each spectral component) results in a sum of sinusoidal output cycles with random phases. In the case of non-linear dynamics, in contrast, the phases of the sinusoidal components of a random output signal are not necessarily randomly distributed, because a sinusoidal input does not necessarily result in a sinusoidal output signal of the same frequency.

Figure 3 shows the distribution of the test statistic as obtained with the phaserandomization approach: This distribution shows non-zero values only within the in-

\section{Nonlinear dynamics during DO events}

H. Braun

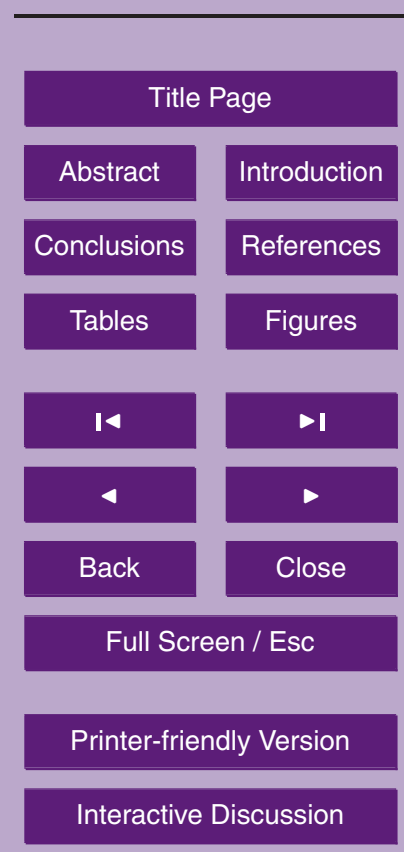

Interactive Discussion

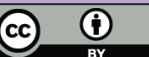


terval between 0.256 and 0.270 . The fact that this interval is narrow is explained by the large number of data points (2447) that are available for the analysis. In contrast to the surrogate time series, the test statistic as obtained from the glacial part of the NGRIP $\delta^{18}$ O-record $\left(M_{\text {NGRIP }}=0.226\right)$ is considerably smaller and does not fall 5 within the simulated test statistic distribution. In this sense, the null-hypothesis that DO events represent a linear, random, time-invariant process is almost certainly wrong, because the average difference between two consecutive data points in the NGRIP ice core record is considerably smaller than expected from such a linear process. In contrast, a much more appealing dynamical scenario to explain the NGRIP record is that

DO events represent nonlinear oscillations in the form of repeated regime switches between fundamentally different states of operation of the climate system. In such a scenario it is intuitively expected that the absolute difference $\left|x_{n+1}-x_{n}\right|$ between two consecutive data points is unusually large during the regime shifts and otherwise small. A similar pattern seems to exist in the NGRIP data (Table 1): When compared with the 15 surrogate time series, in the NGRIP data there is an increased tendency of either small $(<0.3)$ or large $(>0.9)$ values of $\left|x_{n+1}-x_{n}\right|$, whereas the intermediate range $(0.3-0.9)$ is considerably less populated. The interpretation of DO events as regime switches is further supported by the fact that the 40 highest values of $\left|x_{n+1}-x_{n}\right|$ in the ice core time series coincide with the onset or the termination of DO events. If the events were better described by a stochastic linear process, in contrast, it would be expected that high values of $\left|x_{n+1}-x_{n}\right|$ occurred randomly throughout the entire time series, which is apparently not the case. The interpretation of DO events as nonlinear oscillations is also corroborated by the characteristic saw-tooth shape of the events, which is not necessarily expected to result from a linear process.

\section{Discussion and conclusions}

The aim of this study was to test on pure statistic grounds if DO events are consistent with a random linear process or are better explained by a nonlinear process, e.g. by
$5,1751-1762,2009$

\section{Nonlinear dynamics during DO events}

H. Braun

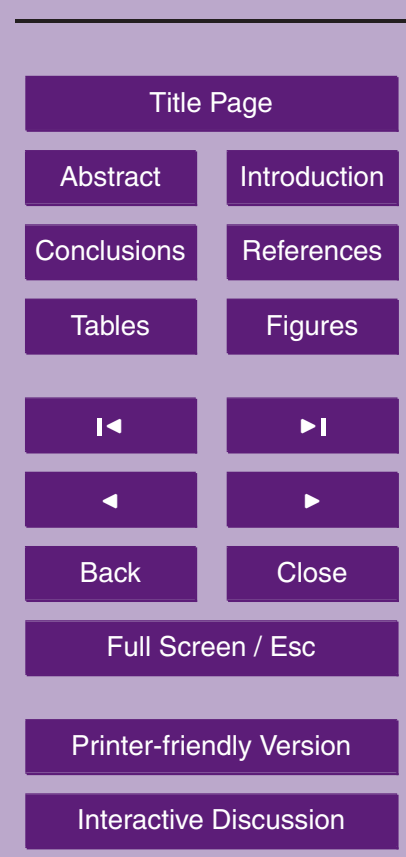

Interactive Discussion

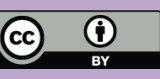


a scenario of repeated regime switchings. Using a nonlinear measure of regularity it was shown that the glacial part of the $\delta^{18} \mathrm{O}$-record from the NGRIP ice core from Greenland almost certainly allows to rule out a random linear scenario. The most direct implication of this finding centres on the misuse of linear time series analysis for 5 the investigation of DO events: Many studies exist in which methods of linear time series analysis have been unthoughtfully used to analyse DO events. For example, the statistical significance of the 1470-year spectral peak in the GISP2 ice core from Greenland has been evaluated on the basis of a first-order autoregressive process (Grootes and Stuiver, 1997; Schulz, 2002), i.e. based on the assumption of a red noise 10 background. However, red noise represents the power spectral density distribution of a linear noise-driven process and is probably not applicable for analysing highly nonlinear oscillations such as DO events, because this approach might yield unrealistically large significance values. Moreover, solar variability as the main century-scale driver of climate has commonly been rejected as a possible trigger of DO events, because

of the lack of a pronounced solar 1470-year spectral component. However, in a highly nonlinear system a 1470-year spectral component in the output does not necessarily require a 1470-year input component, because in such a system a pronounced spectral correlation is not necessarily expected to exist between the forcing and the response. In addition to that, the possible solar role in triggering DO events was questioned because of the lack of a stable phase relationship between DO events and solar proxies (Muscheler and Beer, 2006). However, in nonlinear systems, and in particular in regime switching processes, the existence of a stable phase relationship between the forcing and the response of the system is not necessarily expected.

Being able to show that the events are inconsistent with a linear dynamical scenario 25 provides a relevant benchmark for future statistical analyses on DO events. In particular, it highlights the need to develop and to use more advanced methods of nonlinear time series analysis such as Monte-Carlo simulations (Ditlevsen et al., 2007) and recurrence plot methods (Marwan and Kurths, 2002; Marwan et al., 2007), for example, in order to acquire a better understanding of what triggered DO events and other po-
$5,1751-1762,2009$

\section{Nonlinear dynamics during DO events}

H. Braun

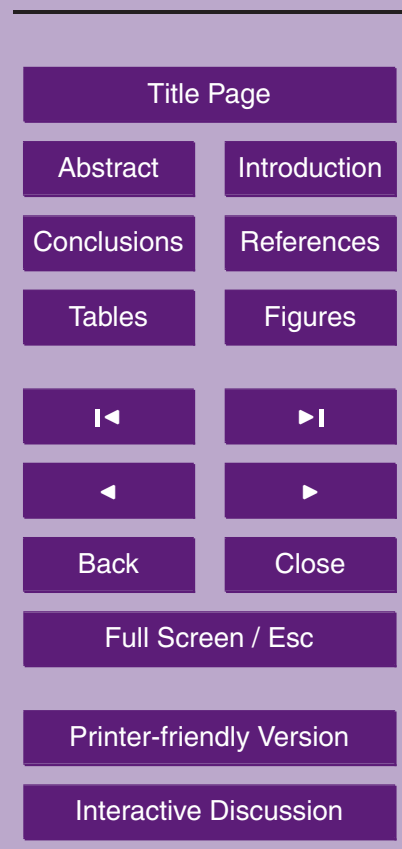


tentially nonlinear paleoclimatic processes.

Acknowledgements. H. B. was funded by the German Research Foundation (DFG), project number: BR 3911/1-1.

\section{References}

5 Alley, R., Marotzke, J., Nordhaus, W., Overpeck, J., Peteet, D., Pielke Jr., R., Pierrehumbert, R., Rhines, P., Stocker, T., Talley, L., and Wallace, J.: Abrupt Climate Change, Science 299, 2005-2010, 2003.

Bond, G., Broecker, W., Johnsen, S., McManus, J., Labeyrie, L., Jouzel, J., and Bonani, G.: Correlations between climate records from North Atlantic sediments and Greenland ice, Na-

10 ture, 365, 143-147, 1993.

Broecker, W. S., Peteet, D. M., and Rind, D.: Does the ocean-atmosphere system have more than one stable mode of operation?, Nature, 315, 21-26, 1985.

Dansgaard, W., Clausen, H. B., Gundestrup, N., Hammer, C. U., Johnsen, S. F., Kristinsdottir, P. M., and Reeh, N.: A New Greenland Deep Ice Core, Science, 218, 1273-1277, 1982.

Ditlevsen, P. D., Andersen, K. K., and Svensson, A.: The DO-climate events are probably noise induced: statistical investigation of the claimed 1470 years cycle, Clim. Past, 3, 129-134, 2007, http://www.clim-past.net/3/129/2007/.

Grootes, P. M. and Stuiver, M.: Oxygen 18/16 variability in Greenland snow and ice with $10^{3}$ to $10^{5}$-year time resolution, J. Geophys. Res., 102, C12, 26455-26470, 1997.

Grootes, P. M., Stuiver, M., White, J. W. C., Johnsen, S., and Jouzel, J.: Comparison of oxygen isotope records from the GISP2 and GRIP Greenland ice cores, Nature, 366, 552-554, 1993.

Kantz, H. and Schreiber, T.: Nonlinear time series analysis, Cambridge Nonlinear Science Series No. 7, Cambridge University Press, Cambridge UK, 1997.

Marwan, N. and Kurths, J.: Nonlinear analysis of bivariate data with cross recurrence plots, Phys. Lett. A, 302, 299-307, 2002.

Marwan, N., Romano, M. C., Thiel, M., and Kurths, J.: Recurrence plots for the analysis of complex systems, Physics Reports 438, doi:10.1016/j.physrep.2006.11.001, 2007.

Muscheler, R. and Beer, J.: Solar forced Dansgaard/Oeschger events?, Geophys. Res. Lett., 33, L20706, doi:10.1029/2006GL026779, 2006.

Nonlinear dynamics during DO events

H. Braun

\section{Title Page}

Abstract Introduction

Conclusions

References

Tables

Figures
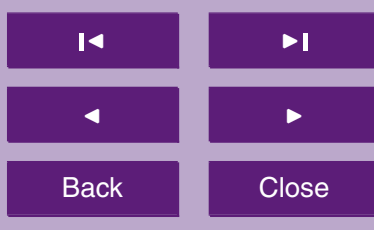

Back

Full Screen / Esc

Printer-friendly Version

Interactive Discussion

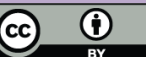


Oeschger, H., Beer, J., Siegenthaler, U., Stauffer, B., Dansgaard, W., and Langway, C. C.: Late glacial climate history from ice cores, in: Climate Processes and Climate Sensitivity, Geophys. Monogr. Ser., 5, edited by: Hansen, J. E. and Takahashi, T., 299-306, AGU, Washington, DC, 1984.

5 Schulz, M.: On the 1,470-year pacing of Dansgaard-Oeschger warm events, Paleoceanography, 17(2), 1014, doi:10.1029/2000PA000571, 2002.

Spötl, C. and Mangini, A.: Stalagmite from the Austrian Alps reveals Dansgaard-Oeschger events during isotope stage 3: Implications for the absolute chronology of Greenland ice cores, Earth Planet. Sc. Lett., 203, 507-518, 2002.

10 Svensson, A., Andersen, K. K., Bigler, M., Clausen, H. B., Dahl-Jensen, D., Davies, S. M., Johnsen, S. J., Muscheler, R., Parrenin, F., Rasmussen, S. O., Röthlisberger, R., Seierstad, I., Steffensen, J. P., and Vinther, B. M.: A 60000 year Greenland stratigraphic ice core chronology, Clim. Past, 4, 47-57, 2008, http://www.clim-past.net/4/47/2008/.
$5,1751-1762,2009$

\section{Nonlinear dynamics during DO events}

\section{H. Braun}

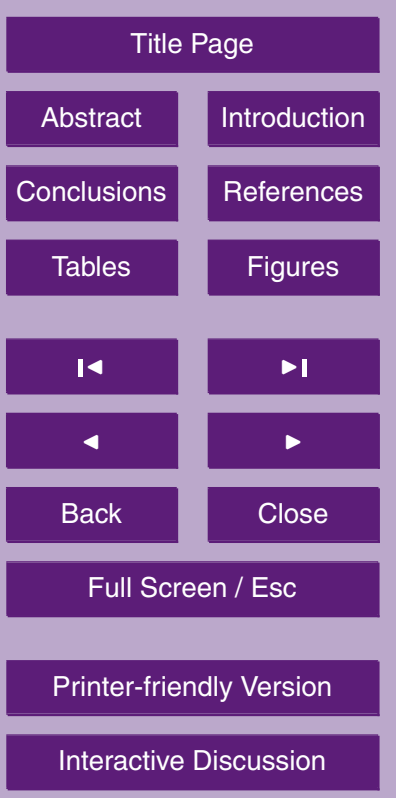


Table 1. Distribution of the distance $\left|x_{n+1}-x_{n}\right|$ (in units of $\delta^{18} \mathrm{O}$ ) between two consecutive data points as obtained from the glacial part of the NGRIP $\delta^{18} \mathrm{O}$ record (Fig. 1a) respectively from the surrogate time series shown in Fig. $2 \mathrm{a}$. The table shows the number of times that the value of $\left|x_{n+1}-x_{n}\right|$ falls within certain bins.

\begin{tabular}{lll}
\hline$\left|x_{n+1}-x_{n}\right|$ & NGRIP & Surrogate \\
\hline $0-0.1$ & 746 & 588 \\
$0.1-0.2$ & 600 & 531 \\
$0.2-0.3$ & 473 & 437 \\
$0.3-0.4$ & 270 & 336 \\
$0.4-0.5$ & 168 & 238 \\
$0.5-0.6$ & 61 & 161 \\
$0.6-0.7$ & 42 & 85 \\
$0.7-0.8$ & 28 & 36 \\
$0.8-0.9$ & 18 & 22 \\
$0.9-1.0$ & 9 & 7 \\
$>1.0$ & 32 & 6 \\
\hline
\end{tabular}

\section{Nonlinear dynamics} during DO events

\section{H. Braun}

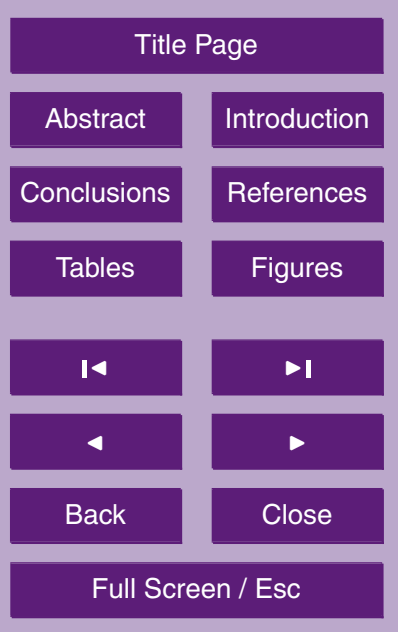

Printer-friendly Version

Interactive Discussion 


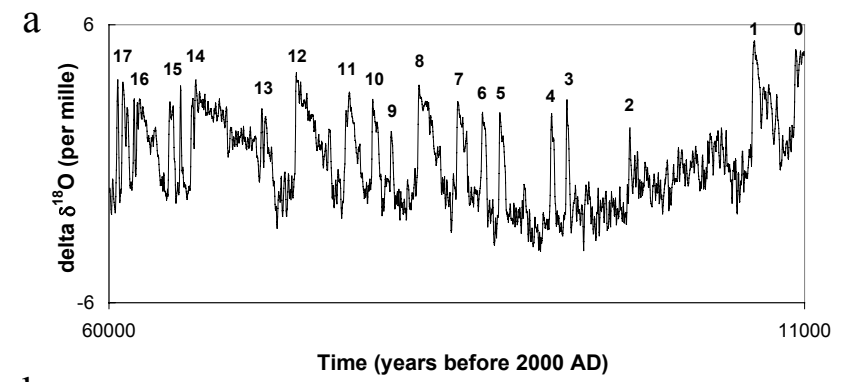

\section{Nonlinear dynamics during DO events}

\section{H. Braun}
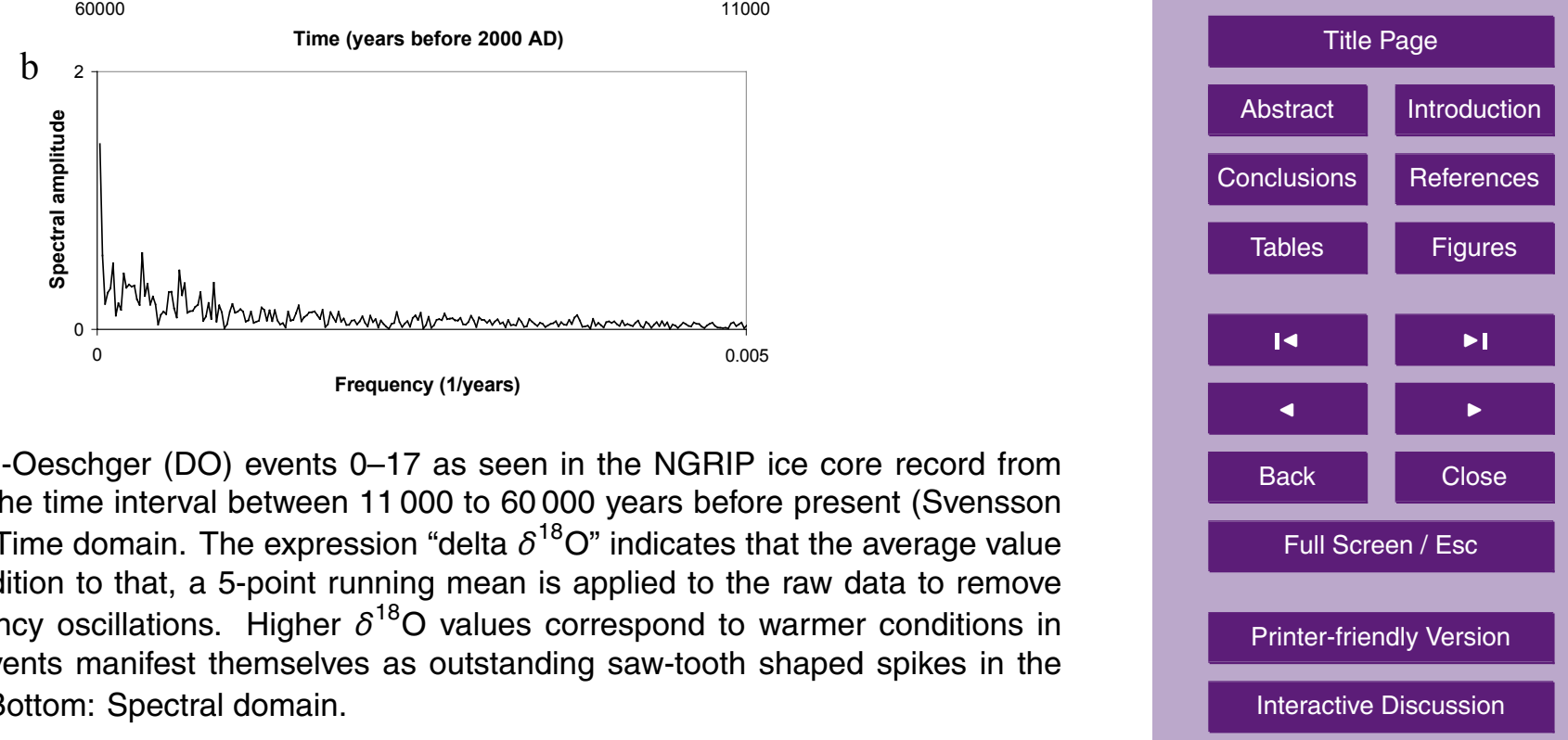

Fig. 1. Dansgaard-Oeschger (DO) events $0-17$ as seen in the NGRIP ice core record from Greenland during the time interval between 11000 to 60000 years before present (Svensson

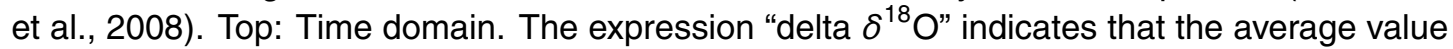
is removed. In addition to that, a 5-point running mean is applied to the raw data to remove the highest frequency oscillations. Higher $\delta^{18} \mathrm{O}$ values correspond to warmer conditions in Greenland. DO events manifest themselves as outstanding saw-tooth shaped spikes in the $\delta^{18} \mathrm{O}$ time series. Bottom: Spectral domain. 


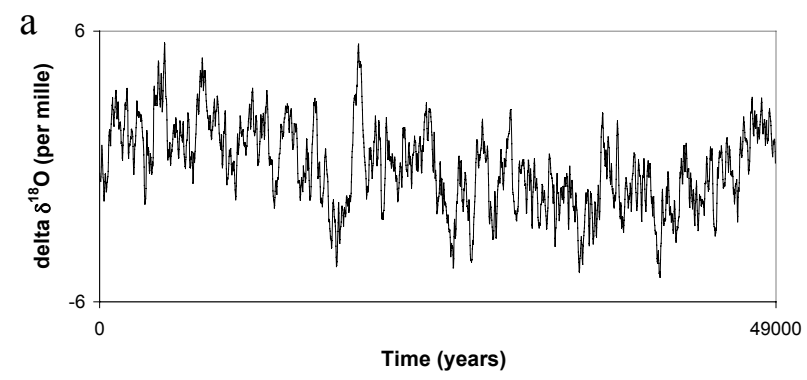

\section{Nonlinear dynamics during DO events}

\section{H. Braun}
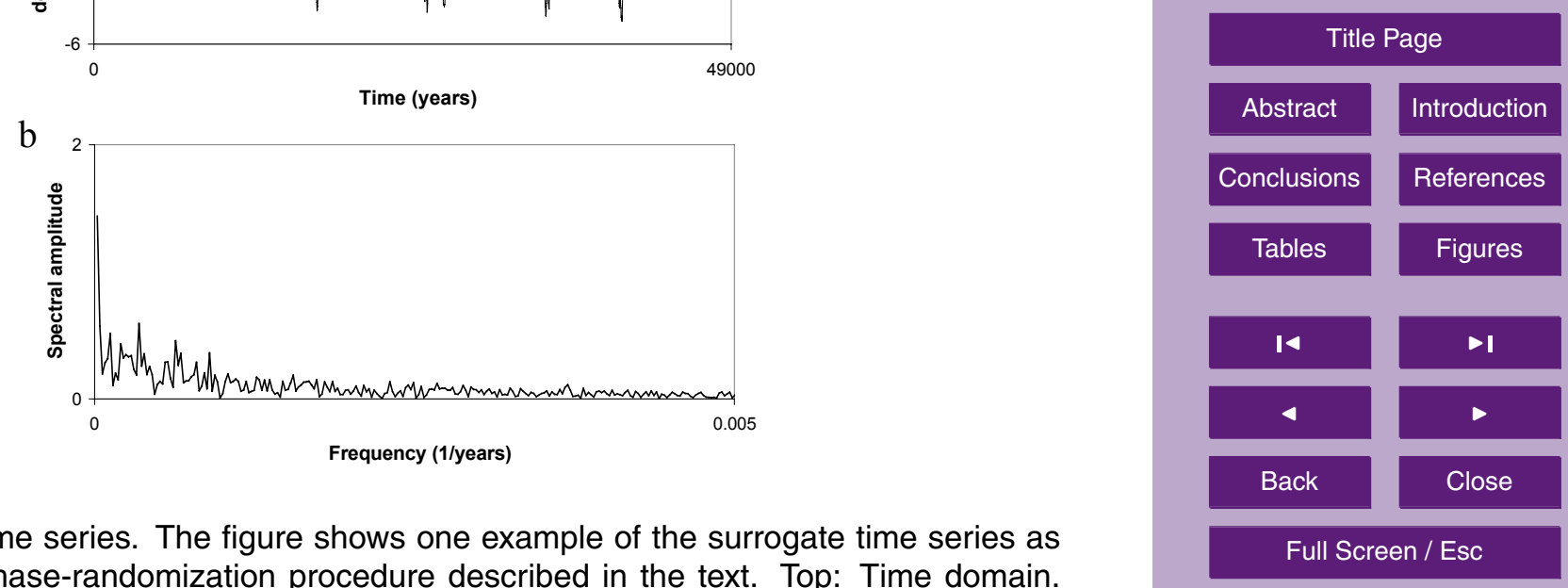

Fig. 2. Surrogate time series. The figure shows one example of the surrogate time series as obtained with the phase-randomization procedure described in the text. Top: Time domain. Bottom: Spectral domain. Note that the amplitude spectrum of each randomized time series is identical to the amplitude spectrum of the NGRIP $\delta^{18} \mathrm{O}$ record (Fig. 1b).

Printer-friendly Version

Interactive Discussion 


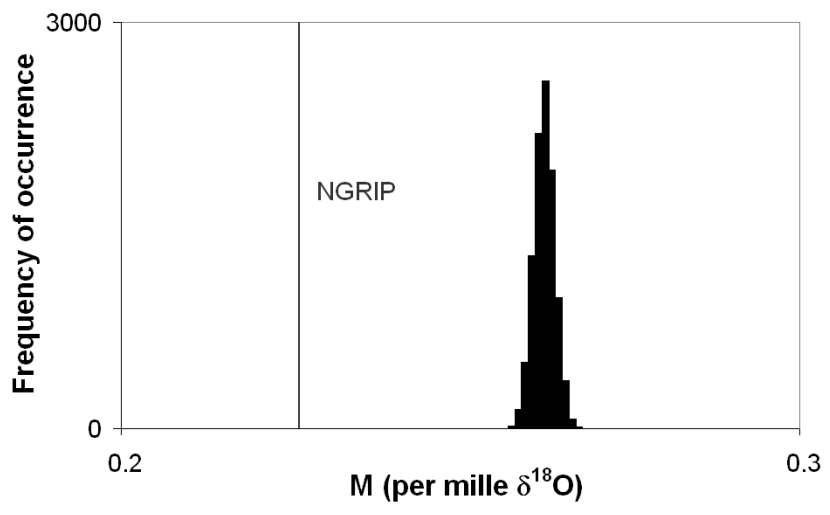

Fig. 3. Monte Carlo simulation. The figure shows the test statistic distribution, i.e. the distribution of the measure $M$ as obtained from the surrogate time series (ensemble size: 10000 members), together with the value obtained from the NGRIP ice core (depicted by the grey line). Note that the $x$-axis starts at $M=0.2$. Beyond any reasonable level of doubt, the value of the test statistic as obtained from the NGRIP $\delta^{18} \mathrm{O}$ record is inconsistent with the null-hypothesis of a random, linear, time-invariant process.

\section{Nonlinear dynamics during DO events}

\section{H. Braun}

\section{Title Page}

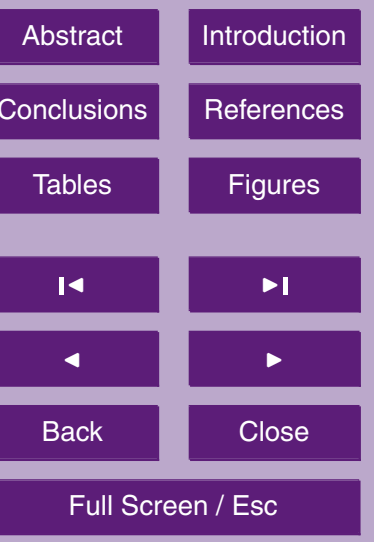

Printer-friendly Version

Interactive Discussion 